\title{
İleri yaşta palmiye (Washingtonia filifera) taşıma süreçlerine dair bir uygulama, İskenderun Teknik Üniversitesi örneği
}

\author{
Sebahat Sinem ÖZYURT ÖKTEN ${ }^{\circledR 1}$, Gökhan PEHLIVAN ${ }^{(D)}$ \\ 1İskenderun Teknik Üniversitesi, Mimarlık Fakültesi, Şehir ve Bölge Planlama Bölümü, Hatay \\ ²Sakarya Büyükșehir Belediyesi, Fen İșleri Dairesi, Sakarya
}

Alınış tarihi: 1 Aralık 2020, Kabul tarihi: 28 Nisan 2021

Sorumlu yazar: Sebahat Sinem ÖZYURT ÖKTEN, e-posta: sinem.okten@iste.edu.tr

\section{Öz}

Amaç: Peyzaj uygulamalarında bitki taşıma yöntemi kullanılarak yaratılmak istenen etki hızlı bir şekilde elde edilmektedir. Ancak yetişkin ağaç -çalıların sökülmesi, taşınması ve alana dikilmesi süreçlerinde, bitkilerin mevcut yaşam koşullarının değişmesi, uygun olmayan taşıma ve iklimsel koşullar nedeniyle ciddi bitki kayıpları yaşanmaktadır. $\mathrm{Bu}$ çalışma gerçekleştirilecek bitki taşıma uygulamalarında bitki ölüm oranlarının azaltılmasına katkı sağlamak amacıyla, transplantasyonu genç bitkilere göre daha zor olan ileri yaştaki palmiye (Washingtonia filifera) bitkilerinin taşınma, dikim yeri hazırlığı ve 2 yıllık gözlem sonuçlarını kapsamaktadır.

Materyal ve Yöntem: Araştırma İskenderun Teknik Üniversitesi kampüs bitkilendirme faaliyetleri kapsamında gerçekleştirilmiştir. Çalışma materyali olan ileri yașta 32 adet ileri yașta Washingtonia filifera bitkisi, çalışmadan 8 ay öncesinde taşıma işlemine maruz kalmış, bu çalışma kapsamında ise taşıma işleminin ardından 1 sene geçmemesine rağmen 2. kez taşıma işlemine maruz kalmışlardır. Uygulamada çıplak kök halinde taşıma yöntemi uygulanmıştır.

Araştırma Bulguları: Çalışma kapsamındaki uygulama 2018 yılı Şubat ayında gerçekleştirilmiştir. Bitkilerin dikim için uygunluğu, dikim yeri toprak yapısı ve iklimsel özellikleri, dikim zamanı faktörlerinden hiçbiri dikim için uygun koşulları sağlamamaktadır. $\mathrm{Bu}$ nedenle standart dikim süreçlerine ek uygulamalar gerçekleştirilmiştir. 75$125 \mathrm{~cm}$ olması gereken dikim yeri derinliği $500 \mathrm{~cm}$ olarak hazırlanmış ve dikim çukuru $50 \mathrm{~cm}$ yükseklikte, mil miktarı yüksek toprakla desteklenmiştir. Taşıma sırasında dallarının çürümemesi için kontakt fungusit ilaçlaması yapılmış, dikim yerine NP gübre çözeltisi ve hümik asit eklenmiş ve dikim sonrası bitkiler çelik halatlarla sabitlenmiștir. 2 yıllık gözlem sonrasında 32 bitkiden 25’i süreci sağlıklı şekilde tamamlamıştır.

Sonuç: Bitki transplantasyon süreçlerinde dikim için uygun koşullar sağlandığında dahi bitki kayıpları \%30 ile \%50'ye kadar çıkabilmektedir. Yapılan uygulamada bitki kaybı \%22'dir. Bu süreçte taşınacak bitki türüyle ilgili literatürlerin ve taşıma deneyimlerinin araştırılması, taşınacak bitkilerin dikime uygunluğunun incelenmesi gerekmektedir. Bitkilerde oluşabilecek hastalıklara karşı ilaçlama ve budama işlemi yapılmalı, dikim yeri hazırlı̆̆ında bitki türüne uygun derinlik ve çap oluşturulurken, toprak yapısı incelenerek gerekli gübre ve düzenleyiciler kullanılmalıdır. $\mathrm{Bu}$ çalışmada karşılaşılan en büyük zorluk olan bitki ve dikim zamanı seçimi uygulayıcıların zaman çizelgesine göre değil, bitkilerin sağlık durumu ve taşıma süreçleri için en uygun dönemler seçilerek planlanmalıdır.

Anahtar kelimeler: Bitki taşıma; Palmiye taşıma; Bitkilendirme; Washingtonia filifera

\section{The Application of Fully-Grown Palm (Washingtonıa filifera) Transport Processes, Iskenderun Technical University Example}

\section{Abstract \\ Objective: The desired effect in landscape applications is ensured quickly with the plant}


transport process. However, in the processes of dismantling, transporting and planting adult treebushes, serious plant losses occur due to changes in the current living conditions, improper transportation and climatic conditions. This study includes the results of transportation, planting site preparation and 2-year observation results of older palm (Washingtonia filifera) plants, whose transplantation is more difficult than young plants in order to contribute to the reduction of plant mortality rates in plant transportation applications.

Materials and Methods: The research was carried out within the scope of Iskenderun Technical University campus planting activities. The study material consists of 32 elderly Washingtonia filifera plants, which were exposed to transportation process 8 months before the study. Within the scope of this study, they were exposed to the transportation process for the second time, although it did not exceed 1 year after the transportation process. Bare root carrying method has been applied in practice.

Results: The application within the scope of the study was carried out in February 2018. None of the factors such as suitability of plants for planting, planting soil structure and climatic characteristics, planting time provide suitable conditions for planting. For this reason, additional applications to standard sewing processes have been implemented. The planting site depth, which should be $75-125 \mathrm{~cm}$, was prepared as $500 \mathrm{~cm}$ and the planting pit was supported by $50 \mathrm{~cm}$ high soil with a high amount of shaft. Contact fungicide was sprayed to prevent rotting of the branches during transportation, NP fertilizer solution and humic acid were added to the planting site and the plants were fixed with steel ropes after planting. After 2 years of observation, 25 out of 32 plants have completed the process in a healthy way.

Conclusion: Even when suitable conditions are provided for planting in plant transplantation processes, plant losses can increase up to $30 \%$ to $50 \%$. Plant loss is $22 \%$ in this application. In this process, it is necessary to investigate the literature and transportation experiences about the plant types to examine the suitability of the plants to be transported for planting. Pesticide and pruning should be done against the diseases that may occur in the plants, the depth and diameter suitable for the plant type should be created in the planting site preparation, the soil structure should be examined and the necessary fertilizers and regulators should be used. The biggest challenge encountered in this study, the selection of plant and planting time, should be planned by choosing the most appropriate periods for the health of the plants and transportation processes, not according to the time schedule of the practitioners.

Keywords: Plant transplantation; Palm transplantation; Planting; Washingtonia filifera

\section{Giriş}

Yerleşimler tarih boyunca çeşitli sembollerle nitelendirilmiş ve bu semboller kentlerin karakterlerini oluşturmuşlardır. Tarihten bu yana doğal bitkisel materyaller yaşam alanlarının sembolleri haline gelmiştir. Kentler bulundukları coğrafyalarda sahip oldukları farklı topoğrafik özellikler, bitkisel örtü, tarihi ve kültürel yapılar gibi değerlerle özgünlüklerini sürdürmektedir. Kentlerin özgün karakterlere sahip olmalarında en etkili faktörlerden biri de yeşil alanlardır (Çakır ve ark., 2017; Kısakürek ve Bayazıt, 2018). Yeşil alan tesisi amacıyla kullanılan doğal bitkisel materyallerin istenilen görsel etkiyi yaratacak duruma gelmesi yıllar sürmektedir. Kullanım alanı şartlarına uygun seçilen türlerin bu süreçteki bakım, sulama, budama gibi ihtiyaçlarının zamanında ve yeterli oranda yapılması gerekmektedir. Kent içinde zaman içerisinde nüfus artışı, kullanım alan değişimleri ve ulaşım alternatiflerinin artması gibi sebeplerle yetişmiş doğal materyallerin yer değişikliği zorunluluğu doğmaktadır. Yıllar içerisinde yetişmiş bitkilerin taşınması ve yeni kullanım alanına adaptasyonu büyük önem taşımaktadır. Bu süreçte sökülme, taşınma, yer hazırlığı, dikim sonrası bakımı canlı materyalin sağlıklı kalması açısından oldukça önemlidir. Yeşil alanları oluşturan bitkiler, sahip oldukları etki düzeyleri kadar korunması ve yaşamsal sürdürülebilirliklerinin sağlanması açısından oldukça emek ve masraf isteyen materyallerdir (Arslan, 2017).

Günümüzün hızlı, yoğun ve değişken yaşam koşulları sonucunda hızlı nüfus artışına bağlı olarak yeni kullanım alanları oluşturulmaktadır. Rekreasyonel alanlar, yollar, yerleşim yerleri gibi alanların yeşil alan tasarımlarında yaratılmak istenilen görsel etkinin hızlı bir şekilde elde edilmesi beklenir (Sağlık ve ark., 2019). Bu uygulamalarda genç çalılıkların kullanımı yetişkin çalıların kullanımı kadar etkili değildir. Genç çalılar 20-30 yıl içinde istenilen etkiyi yaratırken, estetik, fonksiyonel ve iklimsel etkilere 
sahip büyük ağaçların kullanımı ise tasarım sonucunda oluşturulmak istenen etkiyi yaratacaktır (Harris, 1983). Ağaç fidanlarının kullanımında ise yaş almış, boylanmış hatta gölge sağlar hale gelmiş olan ağaçların etkisini yaratılamamaktadır. Bu nedenle özellikle kamusal kullanıma açık alanlarda kullanılacak bitkilerin belirli yüksekliklerde ve formlarda olması beklenir. Özellikle ağaçların binalardan yüksek olarak kullanılması, mekânın tanımlanması için önem arz etmektedir (Anonim, 2020). Peyzaj tasarım ve uygulama sürecinde özellikle yetişkin ağaçların taşınarak kullanılması, küçük ağaç ve çalıların büyüyüp alanda yeterli etkiyi sağlayana kadar geçecek zaman kaybını en aza indirecektir (Harris, 1983). Bu nedenle, hazırlanan peyzaj projelerinde istenilen manzaranın oluşması, olgun ve kalıcı bir izlenim yaratılması ve mevcuttaki yapılara uyumlu bir algı yaratması amacıyla yetişkin ağaç taşıma işlemleri yapılmaktadır (Tattar, 1998).

$\mathrm{Bu}$ çalışmada İskenderun kentinin çevre yolu aksında bulunan ve 2015 yılında kurulmuş olan İskenderun Teknik Üniversitesi kampüsünün giriș bölümünün hızlı ve etkili bir şekilde düzenlenmesi amacıyla gerçekleştirilen ileri yaştaki Washingtonia filifera türünün bitki nakil süreci incelenmiştir. Bitkisel materyal açısından genellikle çalı niteliğinde bitkilerin bulunduğu alanda, hem ilçenin merkezi bir konumunda bulunan üniversitenin giriş bölümünün görsel niteliğinin artırılması, hem de uzun yıllardır çevre yolu aksında yetişerek sembolleşen fakat ulaşım aksında gerçekleştirilen proje sonucu alandan taşınmak zorunda kalınan bitkisel materyalin alana tekrar kazandırılması amaçlanmıştır.

$\mathrm{Bu}$ çalışmanın iki ayrı önemi bulunmaktadır. Bunlardan birincisi bir yıl içerisinde iki kez yer değişikliğine uğrayan ileri yaştaki palmiyelerin(Washingtonia filifera) transplantasyon öncesinde ihtiyaç duydukları sürelerden çok daha kısa bir süre içerisinde ve taşınmalarına uygun olmayan iklimsel koşullarda taşınarak alan adaptasyonun sağlanmış olmasıdır. İkincisi ise dikim yeri olan İskenderun Teknik Üniversitesi'nin kurulduğu alanın 2015 yılı öncesinde havaalanı niteliğinde ve özellikle uygulamanın yapıldığı giriş bölümünün pist yüzeyi olarak kullanılmış olmasıdır(Anonim, 2020). Bu nedenle dikim yeri hazırlığı açısından zorlu bir süreç tamamlanarak transplantasyon işlemi gerçekleştirilmiștir.

Gerçekleștirilecek transplantasyon uygulamalarında bitki ölüm oranlarının azaltılmasına katkı sağlamak amacıyla hazırlanan bu çalışma, transplantasyonu genç bitkilere göre daha zor olan ileri yaştaki palmiye (Washingtonia filifera) bitkilerinin taşınma, dikim yeri hazırlığı ve literatüre göre bitki kaybının düşük olduğu 2 yıllık gözlem süreçlerini kapsamaktadır.

\section{Materyal ve Yöntem}

Hatay ilinin İskenderun ilçesinde 2015 yılında kurulmuş olan İskenderun Teknik Üniversitesi kampüs bitkilendirme faaliyetleri kapsamında gerçekleștirilmiştir. İskenderun Teknik Üniversitesi kampüs alanına 32 adet Washingtonia filifera bitki dikim işlemi gerçekleştirilmiştir. Şekil 1'de görünen çalışma alanında kullanılan yetişkin palmiyeler Haziran 2017'de Pac Meydanından sökülerek İskenderun Belediyesi'ne ait fidanlı̆̆a dikilmiştir. Şubat 2018 tarihinde ise aynı bitkiler belediye fidanlığından sökülerek İskenderun Teknik Üniversitesi kampüsüne dikilmiștir.

Bitkilerin taşınma süreçlerinde çıplak kök halinde taşıma yöntemi uygulanmıştır. Kendir halatlar yardımıyla gövdelerinden bağlanan bitkilerin taşınma süreçlerinde beko ve vinç araçlarından yararlanılmıştır. Dikim yeri hazırlığında ise çıplak kök taşıma yöntemine uygun olarak dikim çukur hazırlığı yapılmıştır. Dikim çukuru bu süreçte kök yumağını tamamen örtecek boyutlarda kazılmış, toprakla beslenmiş ve hazırlanan karışımların dikim çukuruna eklenmesiyle kök kılcallarının beslenmesine imkân sağlanmıştır.
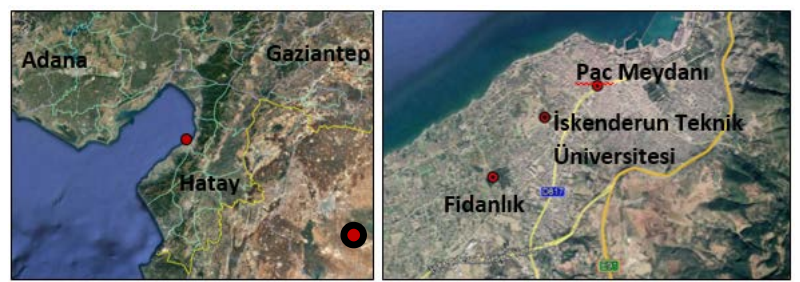

Şekil 1. Çalışma alanı

\section{Bulgular \\ Transplantasyon Süreci}

Transplantasyon olarak da adlandırılan ağaç nakli, belirli bir yaşta olan bitkilerin bulunduğu yerden uygun bir şekilde alınması ve çeşitli amaçlarla istenen etkiyi yaratmak için başka alana taşınması ve dikilmesi olarak tanımlanmaktadır (Harris, 1983; Sağlam, 2013). Ağaç nakil işlemlerinin gerçekleşmesi her ne kadar alan tasarımı için gerekli olsa da bu işlemde temel amaç, ağacın zarar görmemesi olmalıdır. $\mathrm{Bu}$ zararlar dikimden sonra ağaç kayıplarına neden olabilmekte ve ağacın büyüme dönemlerinde de hayati risk devam etmektedir 
(Bainbridge ve ark., 2001; Etemadi, ve ark., 2013; Hiron ve Percival, 2012). Hodel ve ark. (2005)'na göre dikimler \%30 oranında kayıplarla sonuçlanmaktadır. Kurak bölgelerde bu oran \%50'lere kadar çıkmaktadır (Etemadi ve ark., 2013). $\mathrm{Bu}$ nedenle bitki nakil işlemi süreçlerinde söz konusu riskler göz ününde bulundurulmalı ve bitki sağlığını ön planda tutacak kararlar almaya özen gösterilmelidir.

Ağaç taşıma işleminin başlaması için öncelikle bitkinin taşıma ișleminin gerekliliğinin sorgulanması gerekmektedir. $\mathrm{Bu}$ amaçla, taşıma işleminin öncesinde, gerçekleştirilecek uygulamayla ilgili izlenmesi gereken akış şeması Şekil 2'de verilmiştir.

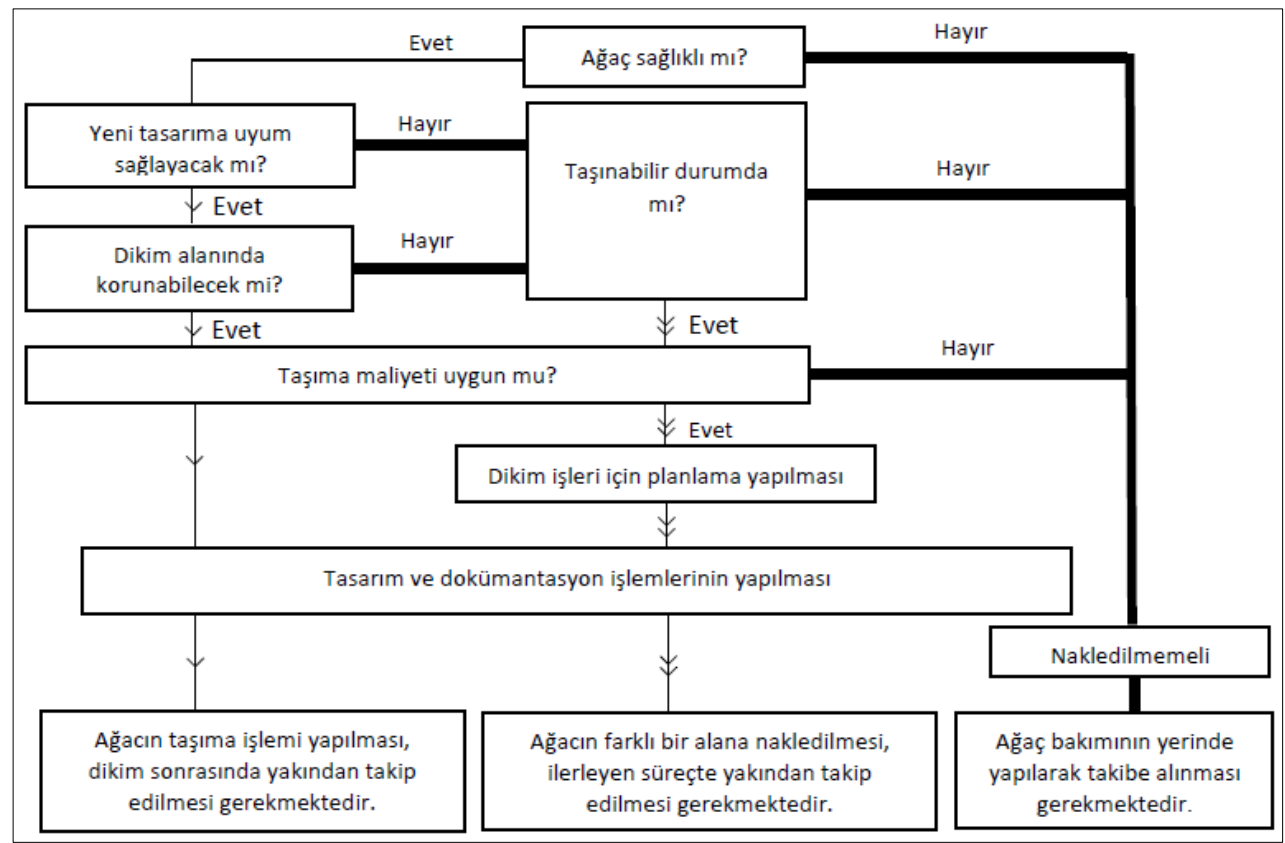

Şekil 2. Ağaç taşıma işlemine karar verme süreci (Development Bureau, 2014'ten geliştirilerek)

Gerçekleştirilecek ağaç nakil işleminin başarılı olması birçok değişkene bağlıdır. Bunlardan biri ağaç nakil çeşididir. Ağaç naklinde kullanılan en yaygın olan taşıma şekli avuç içi naklidir. Ağaç nakli sırasında dikkat edilmesi gereken noktalar ve izlenmesi gereken aşamalar şu şekilde özetlenebilir (Kim, 1988);

1. Kök devamlılığının önemine dayanarak, taşıma ișlemi yapılacak bitkinin kök sağlı̆̆ına dikkat edilmeli ve kök çapı ölçülmelidir.

2. Bitkinin tașındığ olması amacıyla terleme yapmasına neden olacak dallar budanmalıdır.

3. Zemin sıcakken kazılmalıdır.

4. Köklerin topraktan çıkarılma sürecinde kesiler temiz olmalı, bıçak ve testere yardımıyla kesilmelidir.

5. Dikim sırasında yeterli sulama yapılmalı, dikim sonrasında da ağaca püskürtme yöntemiyle de su verilmelidir.

6. Kökler için aljinat hormonu kullanılmalıdır.
7. Gübreleme yapılmalıdır. İdeal olan gübre miktarı ise $1 \mathrm{~m} 3$ alan için 2,8125 kg'dır.

\section{Washingtonia filifera Bitkisinin Yapısal Özellikleri ve Dikim Yeri Hazırlığı}

Yapılan çalışmalar, yaşı ne olursa olsun ağacın kök büyümesi sürecinde yeni köklerin büyüme hızının devamlılığı ve kesilmiş köklerin yeniden büyümesinin ağaç taşıma başarısını artıran temel unsur olduğunu ortaya koymuştur (Tattar, 1998). Washingtonia filifera bitkisinin öncelikli olarak korunması gereken yer, gelișme yeri olan kökün avuç içi kısmında bulunan terminal tomurcuklardır (Development Bureau, 2014). Sökülmesine karar verilen ağaçların 1-2 yıl öncesinden kök çevresinin açılarak kılcal kök vermesi teşvik edilirse dikimden sonra tutması olasılığı artar. Ağaç sökülürken ana ve ince köklere zarar verilmeden sökülmesi, kılcal kökler üzerindeki toprağın korunması gerekir (Harris ve Gilman, 2004). Köklerin zarar görmeden sökülmesindeki başarıya göre değişmekle birlikte ağaç dallarında budama yapılması, yani dal ve yaprak miktarının azaltılması gerekir (Çorbacı ve 
Ertekin, 2012; Demirtaș, 2013; Harris ve ark., 2004). Alınan önlemlerin yanında kök sağlığını etkileyen sorunlardan biri de nakil stresidir. Ağacın taşınma işlemleri sırasında en büyük zararı kök kısmı görmektedir.(Pryor ve Watson, 2016) Genellikle nakil şoku olarak adlandırılan nakil sonrası stres, nakil sırasında kök kaybına uğrayan bitkilerin kuraklık stresinden kaynaklanmakta ve bu kayıplar kök sisteminin \%80 ila \%95'ini bularak ağaç gelişimini yavaşlatmaktadır (Morton Arberatum. 2020; Watson,1996).

Uygulama çalıșmasında kullanılan Washingtonia filifera tek çeneklidir ve az veya hiç dallanma yapmamasından dolayı diğer saçak köklü ağaçlara göre taşınması daha kolaydır (Development Bureau, 2014). Ek olarak yaralı bölgeleri örtmek için yeni doku oluşturabilen bir kambiyuma sahip değildir. $\mathrm{Bu}$ nedenle, dikim işlemi sırasında avuç içlerinin gövdelerine herhangi bir mekanik hasar vermekten kaçınmak önemlidir (Çorbacı ve Ertekin, 2012; Development Bureau, 2014). Tasarım çalışmalarında sık kullanılan, düz, tek gövdeli bir bitkidir ve gövde veya kök çürüklügünü önlemek için çok iyi drene olmuş ve orta derecede tuz toleransı olan topraklara ekilmelidir (Gilman ve Watson, 1994). Palmiyelerde kök yumağı, avuç içini yapısal olarak desteklemek için yeterli kütleye ve derinliğe sahip olmalıdır. Minimum kök bilyesi yarıçapı, aynı zamanda, zemin seviyesinde gövdenin tabanından 6 inç $(15 \mathrm{~cm})$ derinlikte olmalıdır (American National Standard Institute, 2012).

Washingtonia filifera türünün dikim işlemleri çeşitli yöntemlerle yılın farklı zamanlarında yapılabiliyor olsa da, yılın sıcak dönemlerinde yapılması gerektiğine dair çalışmalar bulunmaktadır (Hodel ve ark., 2005; Meerow ve Broschat,1997). Ilıman bölgelerde iklimin kök ve gövde büyümesine olanak verecek koşulları yıl boyu sağlamasına rağmen birçok palmiye türünde kök saçaklanması yaz aylarında meydana gelir (Conkbayır, 2015). Akdeniz bölgesinde kök saçaklanmasını ve gövdenin tutunmasını sağlamak açısından taşınmanın yapılması gereken en uygun dönem Nisan, Mayıs, Haziran aylarıdır. Herhangi bir nedenden dolayı bu aylarda dikim yapılamadıysa en geç Ekim, Kasım ya da Aralık aylarında dikimin gerçekleștirilmesi gerekmektedir (Richardson-Calfee ve ark., 2004; Hodel ve ark., 2005; Esener, 2020). Ayrıca kökler üzerindeki yararlı mikroorganizmaların güneş radyasyonundan zarar görmemeleri için, taşıma işlemi güneşsiz gün ve saatlerde yapılmalıdır.
Palmiye cinsleri için en uygun taşıma dönemi Mayıs ayıdır (Harris, 1983). Palmiye kökleri nakil işlemi sırasında zarar görmeden taşınmalı ve avuç içleri orijinal konumlarından 75-125 mm daha derine konmalıdır (Harris, 1983).

Bitki dikiminden sonraki aşamada ise hareketsizliği sağlamak için avuç içi çelik üstlerle bağlanmal, ancak çivi veya vidalar gövdeye sıkışmamalıdır. Yeni ekilen avuçlarının yaprakları özellikle alkali toprak, soğuk hava koșulları veya manganez veya demir eksikliği nedeniyle solgun olur. Bu nedenle gerekli mineral takviyeleri yapılmalıdır (Harris, 1983).

Tüm bu hazırlık, uygulama ve dikim sonrası işlemlerin uygun olduğu durumlarda dahi bitki kayıpları yaşanabilmektedir. Palmiye taşıma işlemi sırasında, daha önce taşıma işlemine maruz kalmış olan, özellikle 10 yaşını aşmış bitkilerin yeniden taşınması için en az 1 yıl süre ile dinlenmeye bırakılması gerekmektedir. Yapılan uygulamalarda, bitkilere bu süre tanınmadığı takdirde kayıpların yaşandığı görülmüștür (Conkbayır, 2015).

\section{İskenderun Teknik Üniversitesi Transplantasyon Süreci}

Transplante edilecek bitkiler taşıma işlemi için, Hatay Büyükșehir Belediyesi tarafından yapılan kent içi ulaşım planlaması kapsamında gerçekleştirilen "İsmet İnönü-Tayfur Sökmen Birleştirilmiş Entegre Battı Çıktı Projesi" kapsamında gerçekleştirilen yol genişletme çalışmaları kapsamında 2017 yılı Haziran ayında alandan sökülen yetişkin Washingtonia filifera ağaçları kullanılmıştır (Şekil 3).

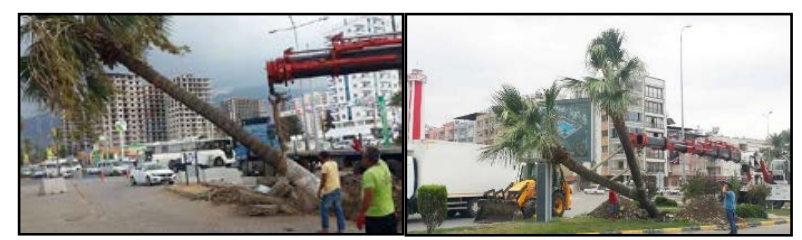

Şekil 3. İskenderun Pac meydanından Washingtonia filifera sökümü

Söküm işleminin yapıldığı Pac Meydanında, gövde boyları minimum $12 \mathrm{~m}$, maksimum $20 \mathrm{~m}$ arası değişen 32 adet Washingtonia filifera, İskenderun Belediyesine ait rüzgâra karşı korunaklı ve drenajı iyi bir alana taşınarak 4-5 m sıklıkta dikilmiştir (Şekil 4).

\section{İskenderun Teknik Üniversitesi Kampüsünün Durumu ve Dikim Yeri Hazırlığı}

İskenderun Teknik Üniversitesi kampüs bitkilendirme çalışmaları kapsamında Sakarya Büyükșehir Belediyesi ile iletişime geçilmiș ve Şubat 
2018 tarihinde kampüste mevcut durum analizi yapılarak ihtiyaçlar ortaya konulmuştur. Kampüsün giriș bölümünde yaratacağı görsel etki düşünülerek yetișkin ağaç arayıșına girilmiștir (Şekil 5). 8 aylık bir süre öncesinde gerçekleştirilecek planlar için geçici olarak belediye fidanlığına taşınmış olan palmiyelerin kullanımı Hatay Büyükșehir Belediyesi tarafından uygun görülmüştür.

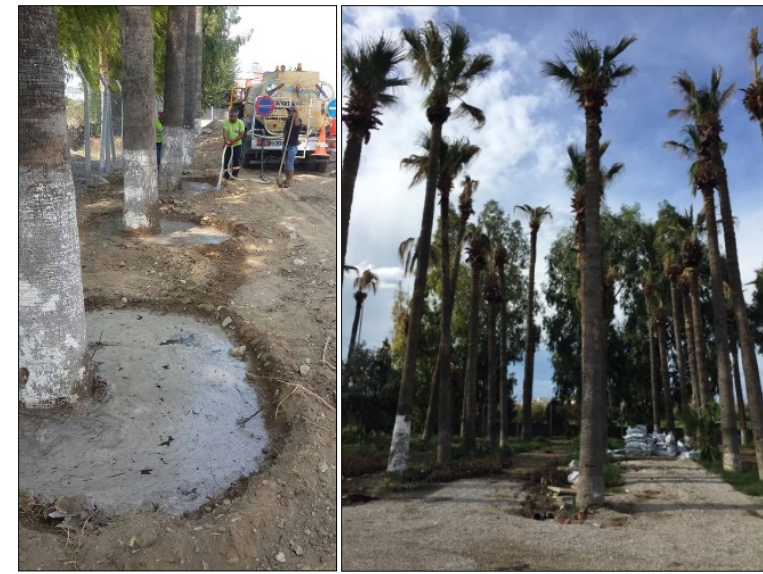

Şekil 4. Taşınan Washingtonia filifera bitkilerinin fidanlıktaki görünümleri

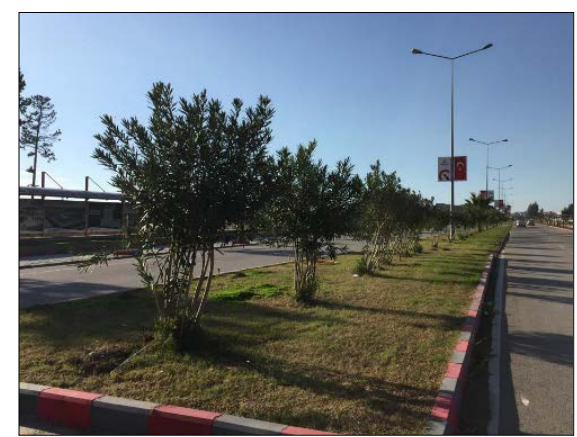

Şekil 5. Transplantasyon öncesi

Uygulamasının ilk gününde dikim yeri hazırlığı yapılmıştır. Palmiyelerin tesis edileceği alanın hazırlık aşamasında öncelikle dikim yapılacak yerlerde sıralı refüj dikimi için $5,5 \mathrm{~m}$ aralıklarla işaretlemeler yapılmıştır. Dikim alanlarının drenajının ve toprak yeterliliğinin sağlanabilmesi için yaklaşık $2 \mathrm{~m}$ çapında ve 2-2,5 m derinliğinde dikim çukurları beko yardımıyla açılmıştır. Dikim çukurlarının derinlikleri imkân dâhilinde geçirimli (drenajı yüksek) tabakaya ulaşana dek kazılmıştır. Asfalt ya da benzeri sert materyalle karşılaşıldığında bu tabaka bekonun ucuna takılan kırıcı yardımıyla kırılmış ve çıkan toprak çok fazla kil ve hafriyat içerdiğinden (alan daha önce belirtildiği gibi havaalanı olarak kullanılmasının ardından hafriyat ve kötü toprak doldurularak yükseltilmiş) alandan traktörlere yüklenerek uzaklaştırılmıștır. Aynı anda boş bir alanda mil miktarı yüksek bir toprakla (2/4) çevreden temin edilen üst yüzey bahçe toprağı (1/4) yanmış koyun - keçi gübresi (1/4) harmanlanarak karıştırılmıştır. Palmiyelerin alana taşınmasından önce hazırlanan bu karışımdan dikim çukurlarının dibine 40-50 cm kadar serilmiş ve çukurlar bol miktarda su ile doldurulmuştur.

Uygulamanın 2. gününde ise palmiyelerin alandan söküm ve dikim işlemleri gerçekleştirilmiştir. Öncelikle fidanlıktan alana taşınacak olan palmiyeler belirlenmiştir. Taşıma işlemi yapılacak olan bitki seçiminde palmiyelerin gövdelerini düzgünlügü, dallanma durumları, söküm yapılacak olan alanda işlem yapma kolaylığı ve dikim yerlerinde elde edilmek istenen vurguya bağlı olarak gövde uzunlukları da dikkate alınmıştır. Fidanlıkta dip çanakları beko yardımı ile çok hassas (gövde ve köklere temas ettirmeden) bir biçimde açılmıştır. Hem beko ucuna bağlı hem de vinç ucuna bağlı kendir halatlar palmiyelere bağlanarak beko ve vincin aynı anda çalışmasıyla yerinden sökülmüş, dalları hassas bir biçimde bir araya getirilerek bağlanmış ve tır dorsesine yüklenerek alana transferi yapılmıştır (Şekil 6).

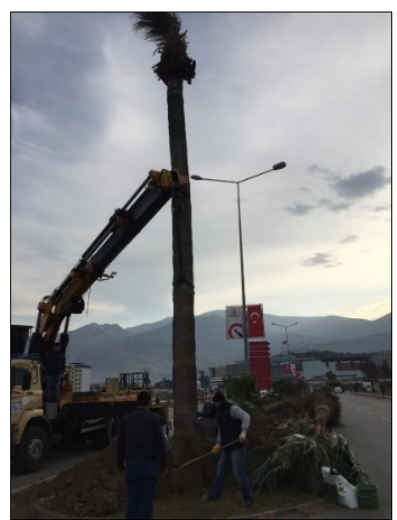

Şekil 6. Taşınan palmiyelerin üniversite kampüsünde dikim işleminin gerçekleștirilmesi

Palmiyeler alana geldiğinde dikilecek her palmiye için yapılan işlemler şu şekilde sıralanabilir;

- Kök - kök boğazı mesafesi uzunluk cinsinden ölçülmüş, yeni yerine dikilecek palmiyenin eski kök boğazı derinliğinden 80-100 cm daha derine gelecek şekilde çukurlara tekrar toprak karışımı doldurulmuştur.

- Dikim çukuruna hümik asit eklenmiş, dikim çukurları 1/3 kadar tekrar su ile doldurulmuştur. Hümik asit, toprağın humus tabakasının alkalide çözünen kısımlarıdır. Hümik asitin dikim alanlarında kullanımının birçok nedeni olsa da söz konusu 
uygulamada kullanılmasının en önemli nedeni kök bölgesinde ideal pH dengesini (5,5-7), ideal organik madde miktarını (\% 4-6) ve mikrobiyolojik aktiviteyi düzenlemesidir (Ay, 2015).

- Palmiyelerin dalları kapalı şekilde kış aylarında taşınmasından dolayı, bölgenin yağış alması durumunda dallarda biriken yağmur sularının çürümeye yol açarak mantara sebep olabileceği düşünülmüştür. Bu nedenle dallar kontakt fungusit ile bolca ilaçlanmıştır.

- Ardından palmiyeler vinç yardımıyla çukura konulmuş ve teraziye alınmıştır. Tüm bu işlemlerden sonra traktör römorklarında hazır bekletilen (daha önce hazırlanan toprak karıșımı ) palmiyeleri sıkı bir biçimde saracak şekilde doldurularak beko yardımıyla dipleri ezilmek sureti ile sıkıştırılmıştır. İnsan gücüyle palmiyelerin etrafına su çanakları yapılmıştır. Su çanaklarının içerisine 20 -20 ( N-P ) suda eriyen gübre atılarak toprak suyu çekene kadar su verilmiştir. Daha sonra palmiyelere gövdelerine takılan özel aparatlar ve zemine çakılan çelik halatlarla tespit işlemi yapılmıştır (Şekil 7). Yeni yerlerine dikilen palmiyelerin toprak nemine göre sulamaları devam etmiştir (Şekil 8).

\section{Sonuç}

Meerow ve Broschat (1997) ile Conkbayır (2015)'ın belirttiği gibi dikimin gerçekleştiği ilk yılda palmiyelerin gelişimine devam etmesi beklenmez. Bu nedenle yapılan uygulama sırasındaki dönemsel iklim koșullarının da etkisiyle bitkilerin adaptasyonun izlenebilmesi için 2 ylllık bir süre tanınmıș ve bu süre sonucunda elde edilen sonuçlar dâhilinde değerlendirme yapılmıştır. Taşıma işleminin gerçekleştirilmesinden sonraki süreçte bitkilerin bağlı olduğu çelik halatlar sökülmemiş, budama, sulama ve ilaçlama işlemleri gibi bakım işlemleriyle İskenderun Teknik Üniversitesi Yapı İşleri Daire Başkanlığı bünyesine bağlı personeller ilgilenmiştir. Harris (1983), Hodel ve ark. (2005) ve Esener (2020)'in belirttiği gibi palmiyeler için uygun dikim zamanları Nisan, Mayıs ve Haziran aylarıdır. Gerçekleșen uygulama ise Şubat ayında yapılmıştır. Washingtonia filifera bitkisinin taşıma işlemlerinde yapılan çalışmalar incelendiğinde kış aylarında gerçekleşen bir uygulama bulunmamaktadır. Gerçekleşen çalışma, uygulamanın kış aylarında gerçekleşmiş olması ve kullanılan palmiyelerin 1 yl içinde 2. kez yer değiștirerek alana adapte edilmesi açısından önem tașımaktadır.

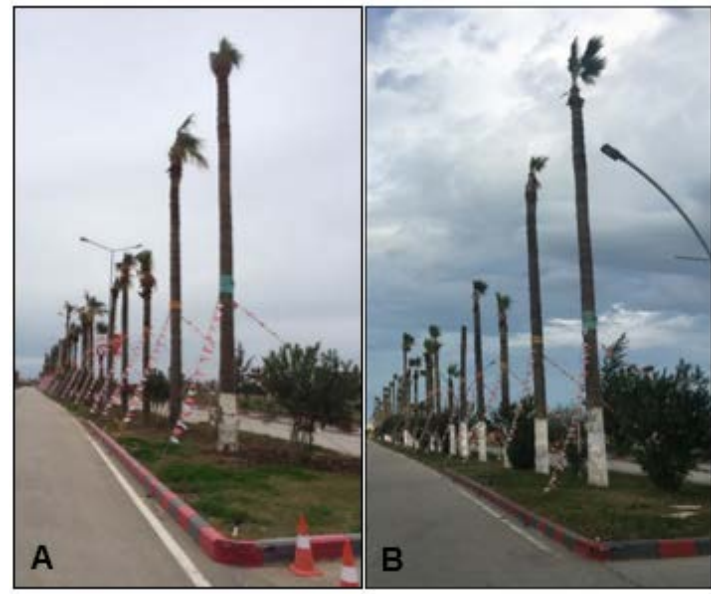

Şekil 7. Transplantasyon sonrası A. 2018 Şubat, B. 2020 Şubat.

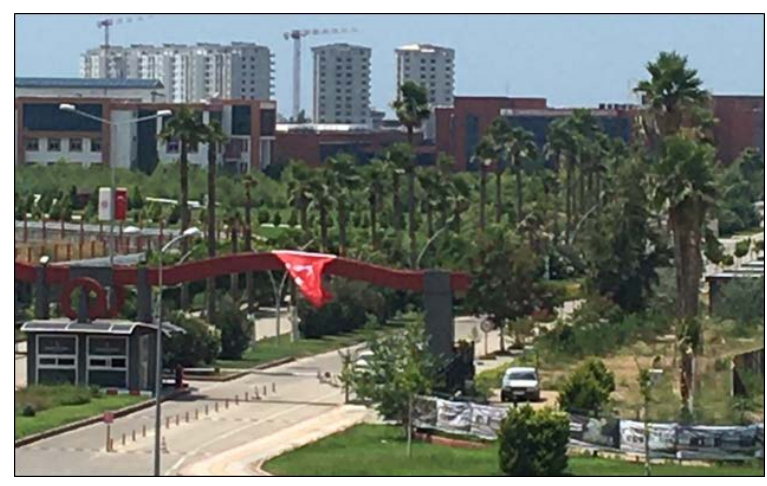

Şekil 8. İskenderun Teknik Üniversitesi kampüs girişinde uygulama yapılan palmiyelerin durumu (09.08.2020)

Taşımanın gerçekleşmesinden günümüze geçen 2 yıllık süreçte 32 adet yetişkin ve sağlıklı Washingtonia filifera bitkisinden 25 adedi sağlıklı şeklide yaşamına devam etmektedir. Bu oran bitki taşıma işleminde \%22'lik bir kayıp yaşandığını ortaya koymaktadır. Ağaç taşıma uygulamalarında Hodel ve ark. (2005)'na göre \%30, Etemadi ve ark. (2013)'na göre koșullara bağlı olarak \%50'lere çıkan ağaç kayıpları ile karşılaştırılacak olursa, gerçekleștirilen uygulama sonucunda elde edilen \%22'lik kayıp oranı, dikimin gerçekleştirildiği iklimsel ve zamansal koşullar dikkate alındığında nispeten başarılı bir sonuç olarak değerlendirilebilir.

Bitki kaybını en aza indirgemek için gerçekleştirilen uygulamadan yola çıkılarak yapılan yanlışlar ve yapılacak palmiye nakil işlemlerine rehberlik etmesi amacıyla dikkat edilmesi gereken konular aşağıda sıralanmıștır; 
1. Gerçekleştirilecek uygulamalarda kullanılan bitkilerin canlı birer materyal olduğu unutulmamalı, yapılacak hataların bitki ölümleriyle sonlanabileceği ciddiyetiyle kararlar alınmalıdır. $\mathrm{Bu}$ nedenle bitki taşıma deneyimleri çok büyük önem taşımaktadır. Özellikle uygulamaya dayalı literatür incelemesi yapıldıktan sonra uygulamaya geçilmesi oldukça önemlidir.

2. Taşıma işlemine maruz kalmış palmiyelerin yeniden taşınması için gerekli olan 1 yıllık dinlenme süresi (Meerow ve Broschat, 1997; Conkbayır, 2015) yapılan uygulamada 8 aylık süreyle sınırlı kalmıştır. Gerçekleştirilecek çalışmalarda sürenin 1 yıla tamamlanmasına dikkat edilmelidir.

3. Dikim yeri hazırlığında Harris (1998)'in belirttiği avuç içlerinin orijinal konumlarından 75-125 mm daha derine konma gerekliliği, yapılan uygulamada sıcaklık, toprak sıcaklı̆̆l, rüzgâr hızı gibi iklimsel faktörlerin etkisiyle $500 \mathrm{~mm}$ kadar derine konulmuştur. Dikim yeri ve zamanı uyumsuzluklarında toprak derinliğini artırmak olumlu sonuçlar doğurabilmektedir.

4. Dikim yapılan 2018 Şubat ayında İskenderun koşullarında saatte 40 km'yi bulan rüzgâr hızına rağmen dikim işlemi yapılmış sonrasında çelik halatlar yardımıla palmiye gövdelerinin zarar görmemesi sağlanmıștır. İleri yaşta palmiyelerin taşınma işlemlerinde özellikle sabitleme işlemi İskenderun gibi zorlu iklim koşullarına sahip alanlarda özellikle dikim zamanı uygun olmayan zamanlarda mutlaka uygulanmalıdır.

5. Özellikle uygulama çalışmalarında katılımcı kurumların mevcut iş yüklerini organize edip katılım sağlamalarında zaman çizelgeleri değişkenlik göstermektedir. Gerçekleştirilecek alan çalışmalarında ağaç kayıplarını önlemek için zaman çizelgelerini dikim zamanlarına göre ayarlamak oldukça önemlidir.

\section{Çıkar çatışması}

Yazarlar arasında herhangi bir çıkar çatışması yoktur.

\section{Yazarların katkı beyanı}

Araştırma, bir uygulama çalışmasının sonuçlarını yansıtmaktadır. Yazarlar SSÖÖ ve GP ilgili uygulamanın sorumlu personelleri olarak süreci yönetmiş ve uygulama sırasında eşit görev almışlardır. Araştırma makalesinin hazırlanma sürecinde ise katkıları aşağıdaki gibidir;
SSÖÖ: Araştırmanın tüm aşamalarına katkıda bulunmuştur

GP: Araștırmanın Transplantasyon Süreci, Washingtonia filifera Bitkisinin Yapısal Özellikleri ve Dikim Yeri Hazırlığı, İskenderun Teknik Üniversitesi Transplantasyon Süreci, İskenderun Teknik Üniversitesi Kampüsünün Durumu ve Dikim Yeri Hazırlığı aşamalarına katkıda bulunmuştur

\section{Teșekkür}

Bu çalışma sürecinde, uygulama alanının bulunması, dikim yeri hazırlığının yapılması ve sonraki süreçte bakım hizmetlerinin yapılmasıyla ilgili İskenderun Teknik Üniversitesi'nin tüm imkânlarını bize sunan İskenderun Teknik Üniversitesi Kurucu Rektörü Sayın Prof. Dr. Türkay Dereli'ye, ağaçların bedelsiz olarak teminini sağlayan, araç ve personel desteğinde bulunan Hatay Büyükșehir Belediyesi Park, Bahçe ve Yeşil Alanlar Daire Başkanı Sayın Mustafa Dönmez'e, İskenderun Teknik Üniversitesi, Hatay Büyükșehir Belediyesi ve Sakarya Büyükşehir Belediyesi ekiplerinin birlikteliğini sağlayan İskenderun Teknik Üniversitesi eski Genel Sekreteri Sayın Yılmaz Çiğdem'e teşekkür ederiz.

\section{Kaynaklar}

Anonim, (2020). İskenderun havalimanı. https://tr.wikipedia.org/wiki/\%C4\%B0skenderun _Havaliman\%C4\%B1 (Erişim tarihi: 12.06.2020).

American National Standard Institute, (2012). ANSI A300 (Part 6)-2005 American national standards for tree care operations - Tree, shrub, and other woody plant management - Standard practices (Planting and transplanting). Tree Care Industry Association, Inc.

Arslan, M. (2017). Kent ağaçları ve koruma yaklaşımları. Plant Bitkisel Tasarım Dergisi. https://www.plantdergisi.com/prof-dr-mukerremarslan/plant-dergisi-kent-agaclari-ve-korumayaklasimlari.html (Erişim tarihi: 07.07.2020).

Ay, F. (2015). Hümik asit ve hümik asit kaynaklarının jeolojik ve ekonomik önemi. Cumhuriyet Üniversitesi Fen Fakültesi Fen Bilimleri Dergisi (CFD), 36(1), Sayfa: 28-51. ISSN: 1300-1949.

Bainbridge, D., Tiszler, J., Macaller, R., \& Allen, M. F. (2001). Irrigation and mulch effects on desert shrub transplant establishment. Native Plant Journal, 2(1), Sayfa: 1-5, DOI: 10.3368/npj.2.1.25. 
Conkbayır, C. (2015). Ağaç taşıma mümkün mü? http://www.yeniduzen.com/agac-tasimamumkun-mu-47686h.htm (Erişim tarihi: 04.06.2020).

Çakır, M., Ezenci, B., \& Topay, M. (2017). Bitkisel tasarımın kent makroformuna katkısı. Plant Bitkisel Tasarım Dergisi. https://www.plantdergisi.com/mertcakir/bitkisel-tasarimin-kent-makro-102ormunakatkisi.html (Erişim tarihi: 24.07.2020).

Çorbacı, Ö. L., \& Ertekin, M. (2012). Private plantation techniques. Landscape planning, Sayfa: 319-352. Yayıncı: Intech Open.

Demirtaş, A. (2013). Toplumu yanıltmada usta'ca yapılan ağaç dikme taşıma işleri. http://www.anafikir.gen.tr/toplumu-yaniltmadausta-ca-yapilan-agac-dikme-tasima-isleri-ahmetdemirtas/ (Erişim tarihi: 24.06.2020).

Development Bureau. (2014). Guidelines on tree transplanting. Greening, landscape and tree management section. The Government of the Hong Kong Special Administrative Region, $33 \mathrm{p}$. https://www.greening.gov.hk/filemanager/conten t/pdf/tree_care/Guidelines_on_Tree_Transplanting _e.pdf (Erişim tarihi: 08.07.2020).

Esener, R. (2020). Palmiye Dikimi. http://www.palmiyemerkezi.com/palmiyelerhak.h tm (Erişim tarihi: 14.07.2020).

Etemadi, N., Nezhad, R.M., Zamani, N., \& Majidi, M. M. (2013). Effect of transplanting date and harvest method on growth and survival of three urban tree species in an arid climate. Arboriculture \& Urban Forestry, 39(5), Sayfa: 211-217.

Gilman, E.F. ve Watson, D.G. (1994). Washingtonia filifera desert palm. https://hort.ifas.ufl.edu/database/documents/pdf /tree_fact_sheets/wasfila.pdf (Erişim tarihi: 02.06.2020).

Harris, R.W. (1983). Arboriculture: Care of trees, shrubs and vines in the landscape, Prentice-Hall. New York. $688 \mathrm{p}$.

Harris, R.W., Clark, J.R., \& Matheny, N.P. (2004). Arboriculture: Integrated management of landscape trees, shrubs, and vines, 4th ed. Prentice Hall. Upper Saddle River, NJ. 578 p.

Harris, R. (1998). Irrigation of newly planted street trees. The landscape below ground II: Proceedings of an international workshop on tree root development in urban soils, Champaign, IL., USA, International Society of Arboriculture.
Harris, J.R., \& Gilman, E.F. (1991) Production method affects growth and root regeneration of Leyland cypress, Laurel oak and Slash pine. Journal of Arboriculture, 17(3), 64-69.

Hiron, A.D., \& Percival, G.C. (2012). Fundamentals of tree establishment: A review. Research Report Forestry Commission, 51-62.

Hodel, D.R., Pittenger, D.R., \& Downer, A.J. (2005). Palm root growth and implications for transplanting. Journal of Arboriculture, 31(4), 171-181.

Kısakürek, Ş., \& Bayazıt, E. (2018). Kahramanmaraș kenti örneğinde kent kimliği ve donatı elemanları. Turkish Journal of Forest Science, 2(1), 49-59. https://doi.org/10.32328/turkjforsci.408372

Kim, H. (1988). Green world. Published by Green Grower, Moreno Valley, 484p.

Meerow, A.W., \& Broschat, T.K. (1997). Transplanting palms. Institute of Food and Agricultural Sciences, University of Florida. http://www.floridaplants.com/Reprints/transplan ting.pdf (Erişim tarihi:12.05.2020).

Morton Arboretum, (2020). Planting and transplanting trees and shrubs. https://www.mortonarb.org/trees-plants/treeand-plant-advice/horticulture-care/planting-andtransplanting-trees-and-shrubs. tarihi:08.08.2020).

(Erişim

Pryor, M., \& Watson, G. (2016). Mature tree transplanting: Science supports best management. The International Journal of Urban Forestry, 38(1), 2-27.

Richardson-Calfee, L.E., Harris, R.J., \& Fanelli, J.K. (2004). Seasonal effects of transplanting on Northern Red Oak and Willow Oak. Journal of Environmental Horticulture, 22, 75-79.

Sağlam, M. A. (2013). Ağaç transplantasyonu, http://www.avrupaparkbahceler.com/makale.php ?baslik=agac-transplantasyonu\& no=12. (Erișim tarihi:14.07.2020).

Sağlık, A., Kelkit, A., Temiz, M., Sağlık, E., \& Bayrak, M. İ. (2019). Millet bahçesi kavramı: Kahramanmaraş ili örneği. Van Yüzüncü Yıl Üniversitesi Sosyal Bilimler Enstitüsü Dergisi, Ek-1 Özel Sayı,11-30, ISSN: 13026879, Van.

Tattar, T. (1998). Large tree transplanting, Landscape Management, 40-43. https://archive.lib.msu.edu/ tic/wetrt/article/1998sep40.pdf (Erişim tarihi: 14.07.2020). 
Watson, G. (1996). Tree transplanting and establishment. Arnoldia, 56(4), 11-16. http://www.jstor.org/ stable/42954498 (Erişim tarihi: 08.06.2020). 